\title{
COMPARACIÓN DE DOS SISTEMAS DE MANEJO EN BÚFALOS RECIÉN NACIDOS HASTA 3 MESES, EN EL MUNICIPIO DE SAN BENITO DE ABAD, DEPARTAMENTO DE SUCRETITULO INGLÉS
}

\author{
COMPARISON OF TWO MANAGEMENT SYSTEMS IN BUFFALO NEWBORN \\ UNTIL 3 MONTHS AGO, IN THE MUNICIPALITY OF SAN BENITO DE \\ ABAD, DEPARTMENT OF SUCRE
}

\section{Carlos José Arredondo Díaz}

Estudiante Zootecnia - Universidad Nacional Abierta y a Distancia UNAD CCAV Sahagún.

\section{Yaneth Galindo Mora}

Médico Veterinario Zootecnista, Docente, Universidad Nacional Abierta y a Distancia - UNAD CCAV Sahagún yaneth.galindo@unad.edu.co

\section{Jaime Hernández Burgos}

Ingeniero Agrónomo, M.Sc. Candidato Ph.D.

Docente, Universidad Nacional Abierta y a Distancia - UNAD CCAV Sahagún.

jaime.hernandez@unad.edu.co

\section{Resumen}

La presente investigación tuvo por objetivo comparar dos sistemas de crías de búfalos manejo (manejo propuesto y manejo tradicional), para bucerros entre 1 día de nacido y el tercer mes de edad, en la finca la Camarga ubicada en el municipio de San Benito Abad, sistema productivo que está siendo afectado por altas tasas de morbilidad y mortalidad en etapa neonatal. Este experimento se realizó bajo un diseño completo al azar con arreglo factorial 2 (manejo convencional vs manejo experimental) $\times 2$ (machos vs hembras), para un total de 4 tratamientos, cada tipo de manejo estuvo conformado por 40 repeticiones para un total de 80 unidades experimental (UE), cada UE fue representada por un DOI: https://doi.org/10.22490/26653176.3560 
búfalo recién nacido. A los dos grupos se les realizó una identificación con chapeta u orejera. El grupo de manejo propuesto quedo conformado por 23 machos y 17 hembras y el grupo de manejo convencional estuvo conformado por 22 machos y 18 hembras, todos con un peso promedio inicial de $35 \mathrm{~kg}$. Se realizó análisis de varianza de acuerdo al diseño propuesto y prueba de comparación de medias de Tukey $(p=0,05)$. El manejo propuesto de bucerros recién nacidos, mejoró el peso final y las tasas de crecimiento de los animales, ya que registró una mayor media en el grupo 1 (48 kg), en comparación al grupo $2(26 \mathrm{~kg})$, en tanto que para las tasas de crecimiento se registró la mayor media en el grupo 1 $(0,53 \mathrm{~kg} \mathrm{dia}-1)$, en comparación al grupo $2(0,29 \mathrm{~kg}$ dia-1). Igualmente, los machos tuvieron mayores tasas de crecimiento $(39,6 \mathrm{~kg})$, en comparación a las hembras $(33,4 \mathrm{~kg})$, asimismo, para las tasas de crecimiento se presentó la mayor media en los machos (0,44 kg.dia-1), en comparación a las hembras $(0,37 \mathrm{~kg}$.dia-1).

Palabras clave: búfalos; morbilidad; mortalidad; manejo.

\section{Abstract}

The objective of this research was to compare two management systems for buffalo calves, for buffaloes between 1 day of birth and the third month of age, in the Camargue farm, a productive system that it is being affected by high morbidity and mortality rates in the neonatal stage. This experiment was carried out under a complete random design with factorial arrangement 2 (conventional management vs. experimental management) $\times 2$ (males vs. females), for a total of 4 treatments, each type of management will consist of 40 repetitions for a total of 80 experimental units, each experimental unit will be represented by one newborn buffalo. The two groups were identified by a group 1 ear flap consisting of the experimental group and group 2 formed by the control group. Group 1 was made up of 23 males and 17 females and group 2 comprised 22 males and 18 females, all with an initial average weight of 35 kilos. Analysis of variance was performed according to the proposed design and Tukey's mean comparison test $(p=0.05)$. The experimental management of newborn buffalo calves improved the final weight and the growth rates of the animals, since it registered a higher mean in group 1 
(48 kg), compared to group 2 (26 kg), while for Growth rates are recorded as the highest mean in group $1(0.53 \mathrm{~kg}$ day-1), compared to group 2 $(0.29 \mathrm{~kg}$ day-1). Likewise, males have higher growth rates $(39.6 \mathrm{~kg})$, compared to females $(33.4 \mathrm{~kg})$, also, for growth rates, the highest average is recorded in males $(0.44 \mathrm{~kg}$.day -1$)$, compared to females $(0.37$ kg.day-1).

Keywords: Buffalos; morbidity; mortality; management.

\section{Introducción}

El búfalo se adapta a cualquier clima entre 1 a 3000 msnm, su rusticidad y su alto \% de reproducción lo convierten en una especie óptima para la producción. De acuerdo con la FAO (2018), la población bufalina en el mundo es de 200.967.747 animales, de los cuales Colombia, según el ICA (2019), cuenta con de 356.908 animales, distribuidos en 3445 predios. Actualmente el búfalo en Colombia está creciendo a una tasa del $30 \%$ anual, mucho mayor a la del ganado vacuno, con un crecimiento del 0,25 $\%$ anual. Además, la producción bufalina tiene una rentabilidad del $63 \%$ en la producción de leche, del $40 \%$ en búfalos de levante y el $42 \%$ en búfalos cebados (Fuente: Afagro Ltda. y ACB, 2016). Estas cifras indican que los sistemas de producción bufalinos son una oportunidad de negocio rentable para productores colombianos y se deben consolidar estrategias de manejo que conlleven a una producción sostenible de búfalos. Los búfalos presentan las mismas enfermedades que el bovino solo que en menores proporciones, presentándose un porcentaje de mortalidad del 3$5 \%$ en etapa neonatal. Un productor, pierde en promedio 720.000 pesos por cría que muere, sin sumar el valor de la leche que no todas las veces es aprovechada, por lo que la mortalidad de las crías es considerada como una de las principales causas de pérdidas en la producción bufalina. Con base en esta información se plantea la necesidad de buscar solución mediante la investigación a la morbilidad y mortalidad del búfalo recién nacido. Por lo tanto el objetivo de la presente investigación se enfocará en comparar dos sistemas de manejo de crías de búfalos, mediante la aplicación de un manual de buenas prácticas bufaleras, para bucerros entre 1 día de nacido y el 3 mes de edad. Ya que viene presentándose una problemática que aqueja a los bucerros a causa del manejo 
tradicional que se viene aplicando a esta especie. De esta manera el presente trabajo permitirá mostrar los resultados positivos esperados en la especie bufalina al ser tratados de una manera adecuada.

\section{Metodología}

Tipo de estudio: El presente estudio es de tipo experimental. Para realizar el trabajo de investigación se tomó un grupo de 80 búfalos divididos en un grupo testigo y otro experimental, a su vez cada grupo se dividió en macho y hembras. A los dos grupos se les realizo una identificación con chapeta u orejera.

Métodos: Los grupos serán trabajados de la siguiente manera:

- Grupo experimental: se le dará un manejo tecnificado que consiste en:

Día 1 . Se realiza el amantamiento si es necesario, en esta investigación no ha sido necesario, ya que los bucerros han recibido el calostro satisfactoriamente.

Día 1 . Se realizó la curación de ombligo con yodo al 7\% dos veces al día, ya que este es el mejor método para desinfectar. La solución del yodo actúa en tres maneras para prevenir la infección. Primero, el yodo limpia la tierra y el estiércol que pueden contener bacterias que causan infecciones. Segundo, el yodo mata inmediatamente a cualquier bacteria presente en el ombligo. Tercero, el yodo ayuda a secar el ombligo e impide que las bacterias entren al cuerpo del bucerro.

Día 7-15. Se realizó la desparasitación de los bucerros en este periodo de tiempo con ivermectina al 3,15\%, a razón de 1 cc por 50 kilogramos de peso, con el objetivo de prevenir la infestación por neoascaris vitulorum, que algunos casos pude ser transmitido por vía intraplacentaria, otra por vía mamaria y en algunos casos es trasmitido antes de nacer el bucerro. Día 10-18. Se realizó la aplicación de vitaminas A, D y E vía intramuscular a razón de $2 \mathrm{ml}$ por animal, con el propósito de evitar el retraso en el crecimiento de las crías, raquitismo y enfermedad del musculo blanco.

Día 30. Se ingresaron las crías al ordeño a esta edad, con la finalidad que el bucerro obtenga los nutrientes necesarios que le brinda la leche en esta etapa. 
Día 30. Se realizó la suplementación con bloques multinutricionales, elaborados sin urea, para evitar la descompensación por perdida de minerales.

Día 31. Se realizó la aplicación de levamisol subcutánea a razón de 2.5 $\mathrm{mg} \mathrm{kg}-1$, con el fin de aumentar las defensas del bucerro. El efecto inmunomodulador del levamisol a respuesta celular hay efecto reconocido sobre linfocito T, CD4 o CD8.

Día 90. Se realizó la vacunación de aftosa en el primer ciclo de vacunación del 2018 a razón de $2 \mathrm{~cm}$ por animal y poder mantener el hato libre de esta enfermedad.

Día 90. Se realizó la vacunación contra la brucelosis a razón de $2 \mathrm{ml}$ por animal, en el primer ciclo de vacunación del 2018 que promueve fedegan, con el fin de tener hembras sanas y excelentes para la reproducción.

Día 90. Se realiza la vacunación contra el carbón sintomático a razón de $2 \mathrm{ml}$ por animal, para poder prevenir la presencia de esta en el hato.

- Grupo testigo: será tratado de manera tradicional.

Día 1. No se cura ombligo.

Día 10. Se ingresa al ordeño.

Día 30. Se realiza la desparasitación para poder prevenir infestación de paracitos internos.

Análisis estadísticos: Este experimento se realizará bajo un diseño completo al azar con arreglo factorial 2 (manejo convencional vs manejo experimental) $\times 2$ (machos vs hembras), para un total de 4 tratamientos, cada tipo de manejo estará conformado por 40 repeticiones para un total de 80 unidades experimental, cada unidad experimental estará representada por un búfalo recién nacido. A los dos grupos se les realizo una identificación con chapeta u orejera grupo 1 conformado por el grupo experimental y el grupo 2 conformado por el grupo testigo. El grupo 1 quedo conformado por 23 machos y 17 hembras y el grupo 2 conformado por 22 machos y 18 hembras todos con un peso promedio inicial de 35 kilos. Se realizó análisis de varianza de acuerdo al diseño propuesto y prueba de comparación de medias de Tukey $(p=0,05)$.

\section{DISCUSIONES Y RESULTADOS}




\section{Anncolae
Habitat}

En el análisis de varianza expuesto en la tabla 1, se observa que tanto el peso final como las tasas de crecimiento fueron afectados por el efecto de los tratamientos de manejo y del sexo. Es decir que se registran diferencias estadísticamente significativas al interior de cada uno de los factores. No se registró interacción tratamiento*sexo en ninguna de las dos variables evaluadas.

La diferencia estadísticamente significativas entre tratamientos para la ganancia de peso al final y tasas de crecimiento, está dado porque se registra una mayor media en el grupo $1(48 \mathrm{~kg})$, en comparación al grupo 2 (26 kg) (figura 1a), en tanto que para las tasas de crecimiento se registra la mayor media mayor media en el grupo $1(0,53 \mathrm{~kg} \mathrm{dia}-1)$, en comparación al grupo $2(0,29 \mathrm{~kg}$ dia-1) (figura $2 \mathrm{a})$. Los resultados muestran el beneficio del realizar un buen manejo a los bucerros recién nacidos, lo cual se ve reflejado en unas mejores tasas de crecimiento y peso final de los animales.

En este sentido, Khan et al. (2007) encontraron una mortalidad de las crías de $17,9 \%$, mientras Khan y Khan (1995) indicaron una mortalidad de $7,1 \%$. Estos autores señalan que la baja tasa de mortalidad encontrada en las fincas gubernamentales de la India puede ser atribuida a mejores prácticas de manejo y alimentación. Por otra parte, Schottler et al. (1977) señalaron valores en becerros criados extensivamente similares a los encontrados en rebaños vacunos. Una mortalidad de becerros de $8,8 \%$ fue encontrada en búfalos de Papúa, Nueva Guinea (Cockrill, 1974), mientras las pérdidas al destete de búfalos de pantano en el territorio norte de Australia fueron 8\% (Ford, 1982). En China, Haipeng y Runpei (1987) encontraron altos valores de sobrevivencia $(92,6$ y $96,3 \%)$ en dos sistemas de producción.

Tabla 1. Cuadrados medios del análisis de varianza de la respuesta del peso final y la tasa de crecimiento de bucerros, en función del

tratamiento de manejo y el sexo

\begin{tabular}{lccc}
\hline Fuente de variación & gl & $\begin{array}{l}\text { Ganancia } \\
\text { de Peso }\end{array}$ & Tasa de Crecimiento \\
\hline Manejo & 1 & $9680.0^{* *}$ & $1.22^{* *}$ \\
Sexo & 1 & $748.9 * *$ & $0.09 * *$ \\
\hline
\end{tabular}




\begin{tabular}{lccc}
\hline Manejo*Sexo & 1 & $2.5 \mathrm{~ns}$ & $0.0003 \mathrm{~ns}$ \\
Error & 76 & 46.9 & 0.005 \\
Total & 79 & 177.1 & 0.02 \\
CV (\%) & & 18.5 & 18.5 \\
R2 & & 0,74 & 0,74 \\
\hline
\end{tabular}

gl: Grados de libertad; **: Diferencias significativas al 1\% $(\mathrm{p} \leq 0,01)$; *: Diferencias significativas al $5 \%(p \leq 0,05) ; C V$ : Coeficientes de variación; R2: Coeficiente de determinación.
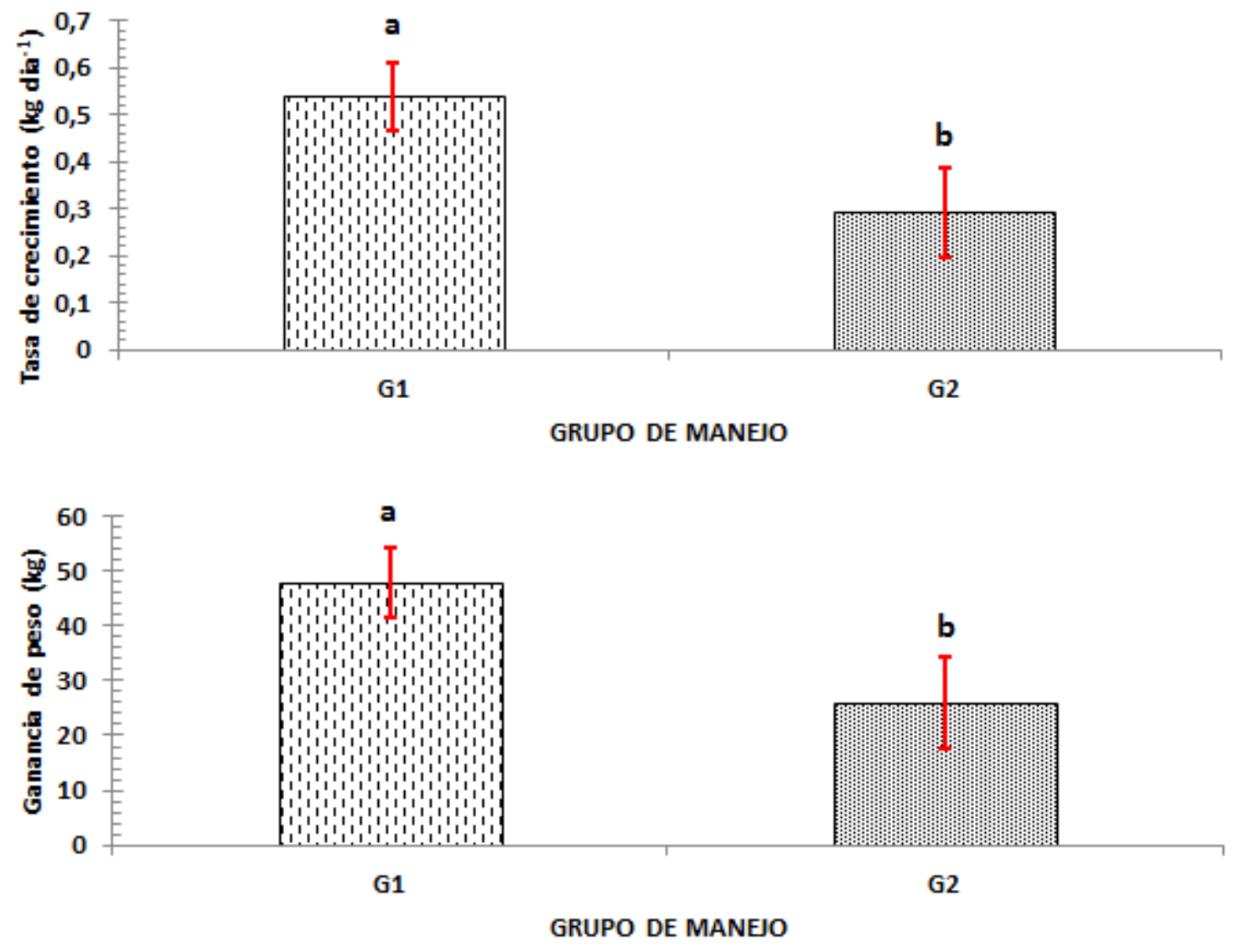

Nota: Promedios con letras similares no difieren estadísticamente, según la prueba de medias de Tukey $(p=0,05)$.

Figura 1. a) Ganancia de peso y b) Tasa de crecimiento de bucerros en función al tratamiento de manejo.

La diferencia estadísticamente significativa entre sexos para el peso final y tasas de crecimiento está dado porque se registra una mayor media en los machos $(39,6 \mathrm{~kg})$, en comparación a las hembras $(33,4 \mathrm{~kg})$ (figura 
2a), en tanto que para las tasas de crecimiento se registra la mayor media mayor media en los machos $(0,44 \mathrm{~kg}$.dia-1), en comparación a las hembras $(0,37 \mathrm{~kg}$.dia-1) (figura $2 \mathrm{a})$. Los resultados muestran claramente que los machos presentan una mayor ganancia de peso y mejores tasas de crecimiento y peso final de los animales.
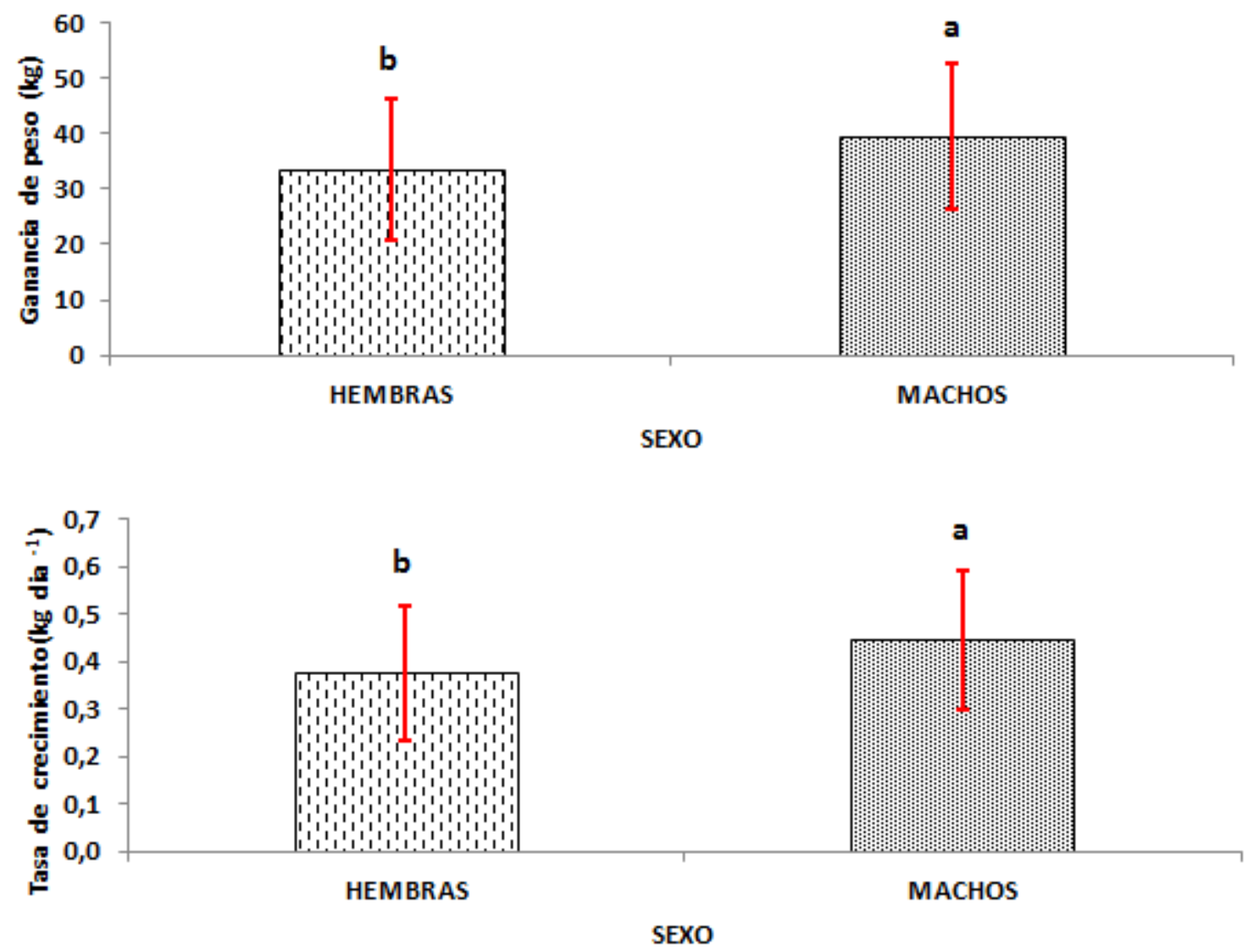

Nota: Promedios con letras similares no difieren estadísticamente, según la prueba de medias de Tukey $(p=0,05)$.

Figura 2. a) Ganancia de peso y b) Tasa de crecimiento de bucerros en función al

\section{CONCLUSIONES} sexo.

El manejo experimental de bucerros recién nacidos, mejora el peso final y las tasas de crecimiento de los animales.

Igualmente, los machos responden mejor tienen mayores tasas de crecimiento. 
Este tipo de manejos podrían ser utilizados como estrategias para consolidar los sistemas productivos bufalinos como una alternativa sostenible en Colombia.

\section{Referencias Bibliograficas}

Agricultura de las américas. (2016) Congreso Mundial de Búfalos. Latinoamérica: Adelasa

Asociación Argentina de Criadores de Búfalos. 1990. Reunión a campo sobre búfalos. Sitio argentino de producción animal.

Asociación Argentina de Criadores de Búfalos. (2006), Sistemas de producción de búfalos en Argentina. Sitio argentino de producción animal.

Camargo, j. (1988), un criador brasileño de bufalos habla de su propia experiencia. Sáo paulo: revista mundial de zootecnia.

Chacón, C., Efraín., Espinoza, E., y Sarabia, Diego. (2017), Antecedentes y diagnóstico situacional de la crianza de búfalos en el fundo valle sacta de la UMSS. Estado Plurinacional Bolivia: Engormix.

FAO. 2018. Estadísticas de producción: ganadería, disponible en: http://www.fao.org/faostat/es/\#data/QA

ICA. 2019. Censo Bufalino en Colombia. Disponible en: https://www.ica.gov.co/areas/pecuaria/servicios/epidemiologiaveterinaria/censos-2016/censo-2018.

Isuiza, M., Peso, R y López, J. (1996), estudio sobre el búfalo de agua en Jenaro herrera. Iquitos: iiap.

Lopez, J. (2018) Principales cuidados en la crianza de bufalos. Engormix. Omar, C., Diana, C., Daniel, V., Pablo, H y Beatriz, B. (2009), Análisis de sobrevivencia hasta el destete de un rebaño bufalino en 


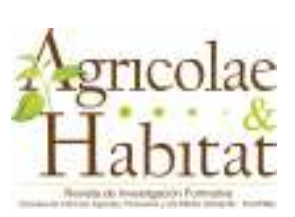

condiciones de sabanas bien drenadas. Maracay: Zootecnia tropical.

Solórzano, F. (1996), Búfalos animales multipropósitos. Caracas. Tonhati, H. (2008), Manejo de búfalos para producción de leche. Departamento de zootecnia 